\title{
Corpos em eterno êxtase: um estudo de caso sobre homofobia cognitiva na revista portuguesa Happy Woman
}

\section{Júnior Ratts e Hamilton Rodrigues Tabosa}

\section{Resumo}

Em 2009, a revista portuguesa de variedades voltada ao público feminino Happy Woman publicou a matéria "Orgasmo: faça sexo como um gay". Tendo como objeto de análise essa matéria, o presente trabalho busca, por meio de uma análise crítica do discurso jornalístico, identificar aspectos homofóbicos em um texto que teoricamente tenta revelar, ainda que de forma conservadora, os homens gays como sujeitos sexualmente ativos e felizes - ou felizes por serem sexualmente ativos.

Palavras-Chave

Homofobia cognitiva. Comportamento sexual. Homossexualidade masculina.

Júnior Ratts | ratts.skc@gmail.com

Bacharel e mestre em Comunicação pela Universidade Federal do Ceará (UFC). Especialista em Artes Visuais e Performáticas pela Universidade do Algarve (Portugal).

Hamilton Rodrigues Tabosa | hrtabosa@gmail.com Doutorando do Programa de Pós-Graduação em Ciências da Informação da Universidade Federal da Paraíba (UFPB). Mestre em Avaliação de Políticas Públicas e Bacharel em Biblioteconomia pela Universidade Federal do Ceará (UFC). Professor do Departamento de Ciências da Informação da UFC.

\section{Corpo e espetáculo: modos de ser e estar na Contemporaneidade}

"O que fazer? Como agir? Quem ser? São perguntas centrais para quem vive nas circunstâncias da modernidade tardia", aponta Giddens (2002, p. 70). "O que fazem, Como agem e Quem são" são afirmações que, geralmente, constituem as matérias dos veículos de comunicação, em especial as revistas de variedades, cujo conteúdo discursivo permite dar relevo à nossa realidade ${ }^{1}$ no instante em que evocam formas de ser e estar no mundo dos vários grupos socioculturais contemporâneos.

Essa ação midiática de mostrar o Outro (e consequentemente o mundo em que esse Outro habita) está diretamente relacionada à construção do $e u$, visto que, conforme aponta Thompson (1998, p. 181): "[...] o processo de formação do self é cada vez mais alimentado por materiais simbólicos mediados". "[...] o desenvolvimento midiático não somente enriquece e transforma o processo de formação do self, ele também produz um novo tipo de intimidade que não 
existia antes". Essa nova forma de intimidade se dá principalmente por meio daquilo que 0 autor intitula de quase-interação mediada, a qual não tem 0 grau de reciprocidade interpessoal de outras formas de interação como a mediada ou a face a face, mas mesmo assim "[...] cria um certo tipo de situação social na qual os indivíduos se ligam uns aos outros num processo de comunicação" (THOMPSON, 1998, p. 80).

Construir então o self dos sujeitos por meio de uma variedade de informações sobre comportamento e personalidade parece ser, de fato, o papel primordial dos produtos midiáticos que trabalham com assuntos do cotidiano, sobretudo, como já apontamos, as revistas de variedades. E dentre as formas mais eficazes de construção desse self destacam-se os discursos acerca do corpo. Em grande parte por ser o corpo o local onde $0 \mathrm{eu}^{2}$ se concretiza (pelo menos em sua exterioridade), é sobre ele que recaem os principais discursos, em especial, os discursos voltados à sexualidade. Mas de que sexualidade falam as revistas? Sibilia (2006, p. 98) nos dá uma luz acerca dessa pergunta quando afirma em seu artigo $O$ corpo editado e a carne impura que

[...] em uma sociedade cada vez mais impregnada pela cultura do espetáculo e pela moral das sensações, a procura pela adequação ao corpo 'perfeito' que se apresenta como modelo universal tem desviado a atenção de setores crescentes da população global no que tange ao cuidado de si.

Ainda sobre o corpo, é interessante registrar que, em 2008, Sibilia lançou um livro intitulado O show do eu: a intimidade como espetáculo. Tal obra decorre de sua tese de doutorado na qual investiga as causas dessa crescente superexposição dos sujeitos, que abrem as portas de sua intimidade para conhecidos e desconhecidos, através de textos verbais e não verbais, buscando compreender de que modo as práticas de espetacularização do eu e da intimidade afetam os modos pelos quais alguém se torna o que é. Nessa obra, Sibilia (2008, p. 233) afirma que na sociedade do espetáculo há uma necessidade de fazer aparecerem as personalidades. As pessoas querem mostrar quem são: "[...] pois o que se cria e recria incessantemente nesses espaços interativos é a própria personalidade". Note que ela usa os verbos criar e recriar, fazendo-nos compreender que, de fato, as personalidades que são mostradas são construtos e não necessariamente refletem a verdade. Sibilia (2003) revela-nos assim que 0

Segundo Virílio (1996, p. 113), "A INFORMAÇÃO é o único 'relevo' da realidade, seu único ‘volume'. Na era da numerização da imagem e do som, deve-se até mesmo dizer sua 'alta definição'.

De acordo com David Le Breton (2003, p. 29), o corpo tornou-se nos dias atuais um "emblema do self". Ainda segundo ele, "[...] a interioridade do sujeito é um constante esforço de exterioridade, reduz-se à sua superfície. É preciso se colocar fora de si para se tornar si mesmo". 
fator motivador da espetacularização de si na contemporaneidade gira em torno da busca pela visibilidade com vistas a serem reconhecidas.

A esse entendimento, Ferraz e Campos (2010, p. 6) acrescentam a existência da espetacularização do corpo,${ }^{3}$ num meio midiático em que "[...] o aparecer e a aparência são fetichizados e tornam-se condição sine qua non de afirmação da existência: ser é aparecer”. Ao tornar-se alvo de tantos discursos e intervenções e de tamanha vigilância e controle, produz-se uma incitação, um aumento do desejo do sujeito por esse corpo. Por vigilância e controle entenda-se 0 que Ferraz e Campos (2010) denominam moral da boa forma, uma moral de ordem estética, que além de produzir a falsa impressão de que 0 corpo encontra-se liberto física e sexualmente, impõe ao sujeito repressões, pois não será qualquer corpo que ganhará espaço na espetacularização midiática: ele deverá se adequar a uma ordem estética social, imposta pela mídia.

Sibilia (2004) acredita que essas novas práticas atravessam a produção de subjetividades na contemporaneidade, transformando-as. Para ela, as noções de intimidade e privacidade são fortemente afetadas. Cada vez mais, a "verdade" que cada um tem para dizer ou mostrar de si se desloca do âmbito íntimo e privado para ser externada na superfície da pele (e das telas).
A espetacularização do eu está entremeada pela excessiva exposição também de grupos nos quais buscamos identidade: homossexuais, militantes, trabalhadores, religiosos, reacionários, estudantes, mulheres etc. Cada um desses grupos sociais, dentre tantos outros, encontram coesão e espaço propício para a comunicação através das novas tecnologias da informação e comunicação. Naturalmente, ao espetacularizar suas lutas e reivindicações, tais grupos acabam arrastando consigo todos aqueles a quem representam, de modo a "carimbar" em cada um de nós as marcas e a identidade que ostentam e defendem. Além disso, a mídia colabora para reforçar estereótipos desses grupos, o que nem sempre é positivo.

A literatura, invariavelmente, reconhece problemas e tece críticas com relação ao fenômeno do espetáculo. Foucault (1985), por exemplo, alerta-nos que a visibilidade é uma armadilha numa sociedade que "canceriza" a vista através do poder disciplinar. Debord (1997), por sua vez, argumenta que a espetacularização nada mais é que um exagero midiático e que a mídia, reconhecidamente benéfica, posto que serve para a comunicação, pode eventualmente chegar a cometer excessos. Segundo Debord (1997, p. 171-172), a mudança mais relevante que toda essa situação trouxe "[...] decorre do fato de a dominação espetacular ter podido educar uma geração submissa a suas leis", ou seja, a cada 
geração estaremos ainda mais familiarizados (e carentes?) à espetacularização de nós mesmos. Zago (2010) salienta que toda essa "publicização" de si pode acarretar também transformações da própria subjetividade contemporânea.

Vivendo então em uma sociedade do espetáculo, a sexualidade ideal - e considerada saudável tende a ser a sexualidade espetacular. Ou seja, aquela cujo corpo, em sua busca por saciá-la, brinca com os extremos em sua descoberta de novas formas e locais de prazer; aquela que é reflexo do que 0 senso comum considera como sendo excepcional, ainda que à custa de uma visão limitante, caricatural $^{4} \mathrm{e}$ estigmatizante. Isso porque as dicas que envolvem o cuidado de si são perpassadas por uma seleção da informação, cujo princípio é a busca pelo sensacional. Esse sensacionalismo opera-se por meio daquilo que Bourdieu (1997, p. 25) chama de "óculos especiais" a partir dos quais "os jornalistas vêem certas coisas e não outras; e veem de certas maneiras as coisas que veem. Eles operam uma seleção e uma construção do que é selecionado". Essa seleção se baseia, pois, em uma realidade cada vez mais construída a partir de uma propulsão de signos que se materializam em discursos absolutistas e arbitrariamente naturalizantes sobre os vários sujeitos e seus corpos. ${ }^{5}$ Dessa maneira, a intimidade dos indivíduos alcançados pela mídia vive à mercê de imagens e palavras que constroem ideologias normativas sobre os corpos e suas subjetividades.

É o caso da matéria "Sexo como um gay", veiculada pela revista portuguesa Happy Woman, em 2009. Sucessora de outra matéria que, na mesma edição, prometia às leitoras sua conversão em uma estrela pornô para seus companheiros, 0 artigo em questão, ainda ao evocar a necessidade das mulheres em agradar seus parceiros, traz a seguinte cabeça: "Quer melhorar sua vida sexual? Apetece-lhe sentir-se mais desejada? Procura ter mais prazer na cama e fora dela? A fórmula é simples. Aprenda a fazer sexo como um gay" (ANDRADE, 2009, p. 168).

0 que interessa a este trabalho é compreender que corpo homossexual masculino é construído a partir dos enunciados sobre como seria esse suposto sexo gay. Ou seja, ainda inspirado por Giddens (2002), interessa-nos saber como esse

De acordo com Roland Barthes (1990, p. 184-185), “[...] na cultura de massa, o fato já não é mais um elemento do mundo natural, o que parece como fato é o estereótipo: aquilo que todo mundo vê, que todo mundo consome" Segundo Nunan (2003, p. 61), "[...] como vivemos sobrecarregados de informações, tendemos a nos poupar de gastos desnecessários de tempo e energia cognitivas e utilizamos o estereótipo como um atalho para entende o complexo mundo que nos rodeia".

De acordo com Louro (2008, p. 81), "não há corpo que não seja, desde sempre, dito e feito na cultura; descrito nomeado e reconhecido na linguagem, através dos signos, dos dispositivos, das convenções e das tecnologias". Assim, os meios de comunicação e, neste caso, as revistas de variedades são formas de tornar o corpo reconhecível a partir de uma série da linguagem que compõe guias de normalização que são impostados aos corpos para seu alcance do prazer. Esses guias ao mesmo tempo em que prometem uma liberação do corpo, conduzem-no a olhar o mundo de forma caricatural, como poderei demonstrar neste trabalho. 
corpo se constrói com base na resposta a $O$ que fazem, Quem são e Como agem os gays a partir do ponto de vista de um olhar heterossexual feminino - a matéria é escrita pela jornalista Graça Andrade - e como esse olhar, ao materializar-se em discurso, denota a existência de uma homofobia cognitiva (BORRILL0, 2010) e, por conseguinte, ultrapassa os limites da ética jornalística.

\section{A homofobia cognitiva em meio à conquista do orgasmo}

A homofobia cognitiva, nas palavras de Borrillo (2010, p. 25), “[...] serve de fundamento a um saber sobre o homossexual e a homossexualidade baseado em um preconceito que o reduz a um clichê". É interessante perceber a presença desse tipo de homofobia logo no início da matéria de que trata este estudo, visto que a jornalista apela ao senso comum para descrever os gays como sujeitos que "não só têm mais sexo como têm melhor sexo". Longe de explicitar qualquer contato prévio à escrita da matéria com algum grupo de homossexuais masculinos a fim de saber como eles realmente são e agem em sua vida privada, a jornalista os define como pessoas que fazem sexo em "diferentes posições em locais diferentes, com pessoas diferentes".

No sentindo em que a relação sexo e sujeito é empregada já no começo da matéria, vê-se uma visão absolutista e redutora que remonta às primeiras definições históricas sobre as sexualidades, principalmente a homossexual.
Assim, ao invés de criar uma matéria esclarecedora sobre homens que praticam - e como a praticam - a homoafetividade, a jornalista utiliza o sexo como dispositivo para compreender a individualidade de um grupo que aparentemente desconhece, sobrepujando as características individuais a uma ideia objetiva do que ela acredita ser um homossexual masculino em seu contexto afetivo-sexual.

Dois pontos precisam ser analisados sem nem ainda chegarmos ao segundo parágrafo da matéria. Primeiro, mesmo que de forma não intencional, a autora nos leva a crer na imagem do homossexual como se ele fosse um personagem, um tipo, uma forma de vida, uma morfologia cuja satisfação de seus desejos sexuais é apresentada como um critério imprescindível para a preservação de sua existência: "Na comunidade gay, há certas questões que nem se colocam. Ninguém diz que este ou aquele comportamento sexual é 'impróprio' ou 'pervertido'. Pura e simplesmente, não se fazem juízos de valor", diz Andrade (2009, p. 16). Tal descrição nos remete aos escritos da socióloga Adriana Nunan (2003) acerca dos estudos oitocentistas sobre a homossexualidade, cujo ápice se deu com a organização do catálogo de anomalias sexuais pelo médico alemão Kraft-Ebing, cuja influência e prestígio, de acordo com Costa (1992, p. 80), "[...] sequer foram abalados por Kinsey e por toda a força da mídia norte-americana". Assim a sexologia do Século das Luzes, "[...] a despeito de seu fervor científico, não era nem neutra nem 
simplesmente descritiva. Dizia o que deveríamos ser e 0 que fazia de nós seres normais" e "[...] uma vez imposto o tipo do 'homossexual', tornouse impossível escapar dele. As práticas sexuais passaram a ser 0 critério de descrição da pessoa" (BADINTER, 1993, p. 105).

Como se vê, as maneiras oitocentistas de pensar o sexo continuam a permear a escrita pseudocientífica das revistas de variedades, que, por meio de suas dicas para o desenvolvimento de uma sexualidade considerada saudável, revelam como o poder do senso comum se sobrepõe ao conhecimento profundo de um determinado grupo sociocultural. Ou seja, como a cultura moderna tem sido caracterizada "[...] pela preponderância daquilo a que podemos chamar o espírito objetivo sobre o espírito subjetivo" (SIMMEL, 2004, p. 90). E é este 0 segundo ponto a ser tratado.

Se 0 senso comum prevalece sobre as manifestações da individualidade na produção de sentido,${ }^{6} \mathrm{e}$ se resiste ainda em nosso pensar sobre o sexo, os meandros tradicionais de uma sexualidade normalizada pelo peso da reprodução e pouco instigada a manifestar-se unicamente objetivando o prazer, é evidente que o homossexual continue a ser visto como a antítese da figura do homem-pai, ou seja, como a sexualidade desviada e desviante que não enxerga nenhum tipo de limite físico e moral em sua promoção. É o que parece nos descrever Andrade (2009, p. 46) ao afirmar que "[...] os heterossexuais - e as mulheres, sobretudo - são bem mais contidos. Traçam, normalmente, uma linha bem definida, a vermelho, entre 0 normal e 0 perverso, entre 0 aceite e 0 não aceite". No sentido contrário, "os gays sabem que chupar os dedos é muito sexy. E fazem-no sem pudor nem embaraço". É assim, então, que ficamos a saber o que fazem e como agem os personagens que possuem o "melhor sexo", mesmo que à custa de uma sexualidade considerada promíscua em suas formas de ação e em seus locais de prática: "As mulheres normalmente esperam até chegar ao quarto e à cama para fazer sexo. 0s gays, por outro lado, têm uma maior urgência e fazem-no por toda a casa. É simplesmente onde apetecer". Partindo do princípio de que 0 "discurso nunca possui uma só dimensão" e de que o "corpo é escrito com significantes" e, portanto, é "sobrescrito/superado pela linguagem" (FINK, 1998, p. 29-30), podemos chegar a uma primeira conclusão de que a matéria, por meio da descrição que constrói do que é ser um gay, realiza-o por meio de um discurso que faz do sujeito e de sua sexualidade um aspecto único. Quer dizer, os enunciados da jornalista reduzem a tridimensionalidade do sujeito ao teoricamente valorizá-lo. Teoricamente porque, ao se utilizar de um preconceito considerado positivo, ${ }^{7}$ reafirma mitos das tradicionais ideias preconcebidas sobre

"As reservas de sentido objetivadas e processadas pela sociedade são 'conservadas' em reservatórios históricos de sentido e 'administradas' por instituições. 0 agir do indivíduo é moldado pelo sentido objetivo, colocado à disposição pelos acervos sociais do conhecimento e comunicado por instituições através da pressão que exercem para seu acatamento" (BERGER, 2004, p. 25). 
os homossexuais, dentre elas, a de que o sexo incomum/anormal - por conta de seus excessos - é por excelência o sexo gay. Nesse sentido, a autora não somente estigmatiza ${ }^{8}$ os homossexuais, mas reduz também as potencialidades sexuais de homens e mulheres heterossexuais ao colocá-los abaixo dos gays na hierarquia das práticas sexuais justamente por não saberem se entregar de forma correta (em demasia) aos desejos carnais.

Dessa forma, o corpo que é construído pela matéria da revista é um corpo desprovido de limites físicos e morais: "As mulheres raramente incitam a palmadinhas. Os gays, pelo contrário, são na maioria grandes apreciadores" e "Os gays têm normalmente relações abertas ou semiabertas". Nota-se, nessa última sentença, que aos gays é imputado, pela autora, a incapacidade da monogamia e de desenvolver uma ação sexual considerada "normal". A autora, portanto, reafirma a ideia de que os homossexuais são indivíduos vitimizados por seus desejos - visto que são constituídos por suas compulsões sexuais - e, dessa maneira, reforça a imagem de que a homossexualidade, em última instância, trata-se de fato de uma doença mental e de um desvio de comportamento. Sendo assim, mais uma vez vemos comprovados os aspectos homofóbicos do texto, já que "[...] à semelhança de qualquer forma de exclusão, a homofobia não se limita a constatar uma diferença: ela a interpreta e tira suas conclusões materiais" (BORRILLO, 2010, p. 16). E ainda: comprova-se o olhar masculinista acerca dos gays - mesmo que se trate de um texto escrito por uma mulher. Isso porque, ao tecer uma matéria que estigmatiza os homossexuais e reduz o potencial sexual feminino - a autora reitera o tempo todo que as mulheres são pouco audazes sexualmente -, a jornalista nos confirma que "as imagens e as narrativas da cultura da mídia estão saturadas de ideologias e de valores [...] que reproduzem valores e modos de vida capitalistas e masculinistas dominantes" (KELLNER, 2001, p. 316).

\section{Onde estará a ética em meio à necessidade pelo orgasmo?}

Pensar numa matéria jornalística que produza e reproduza, ainda que nas entrelinhas, uma imagem dos homossexuais a partir de valores/olhares heteronormativos é altamente preocupante, visto que, retomando Thompson (1998, p. 202), o indivíduo que "consome" mídia “está explorando possibilidades, imaginando alternativas, fazendo experiências com 0

Apesar do conceito relacionado ao preconceito ser utilizado pela maioria dos psicólogos sociais e pela população em geral para se referir a atitudes negativas, segundo Nunan, um indivíduo pode ter preconceito a favor de homossexuais. Contudo, seja positivo ou negativo, o preconceito se baseia no estereotipo e "significa atribuir características pessoais ou motivos idênticos a qualquer pessoa de um grupo, independente das variações individuais” (NUNAN, 2003, p. 59).

De acordo com Borrillo (2010, p. 13), "a homofobia é uma manifestação arbitrária que consiste em designar o outro como contrário, inferior ou anormal; por sua diferença irredutível, ele é posicionado a distância, fora do universo comum dos humanos". 
projeto do self". Quer dizer, a leitura de um texto homofóbico em sua essência pode, como consequência, se não produzir sujeitos homofóbicos, pelo menos, alimentar a imaginação homofóbica. ${ }^{9}$ Por isso, a responsabilidade com a ética se faz fundamental na escrita de um texto informativo, principalmente se 0 material possui um objetivo claro de intervir nas manifestações físicas e subjetivas dos sujeitos aos quais é destinada sua leitura. As balizas da ética são, de acordo com Di Franco (1995), a mola propulsora das verdadeiras mudanças. Revelando-se completamente contrário à mudança ao paradoxalmente incitá-la, o texto jornalístico de Andrade (2009) revela como o corpo ainda é um construto da materialidade do poder se exercendo sobre ele. No caso da matéria, do poder heterossexual masculino informando sobre 0 corpo gay ao mesmo tempo em que delineia seus contornos físicos e subjetivos (FOUCAULT, 1999, p. 146). Ainda citando Foucault, matérias como a aqui analisada revelam, de forma constrangedora, que 0 espírito vitoriano ainda habita 0 imaginário cultural e que ele se materializa em artefatos midiáticos cujo falar sobre sexo é transformado em "[...] uma coisa que não se deve simplesmente condenar ou tolerar, mas gerir, inserir em sistemas de utilidade, regular para 0 bem de todos, fazer funcionar segundo um padrão ótimo". Ou seja, "0 sexo não se julga apenas, administra-se" (FOUCAULT, 1998, p. 27).
Ou se administra a partir de um julgamento muito sutil. Seja como for, é, no mínimo, irônico utilizar textos que abordam a sexualidade do século XVIII para tratar de escritos sobre o sexo de agora. É ainda mais irônico uma jornalista falar sobre quem são, como agem e o que fazem os gays somente a partir das experiências de mulheres que leram o livro Sextasy no qual sua autora, a britânica Tracey Cox, dedica um capítulo inteiro a explicar como se pode aprender a fazer sexo como um gay. Em meio a essas várias vozes femininas e heterossexuais, perguntamo-nos: quais os empecilhos de incluir a fala de um ou mais homens gays, que rebatessem/negassem/questionassem ou confirmassem as conclusões da jornalista, de Cox ou de qualquer uma das entrevistadas?

Como falamos no início da segunda seção, é o senso comum, a homofobia cognitiva que guia o texto de Andrade (2009) o qual vai de encontro a um jornalismo competente de fato; $;^{10}$ a materialidade dos discursos sobre 0 corpo na matéria se dá a partir de um olhar sexista que, em suma, reduz a sexualidade heterossexual a uma experiência humana sempre em busca por novidades e materializa a experiência sexual gay como uma ação pós-humana, visto que ela depende de uma energia incomum que termina por transformá-la em um mito sexual e que continuará a não fazer parte de uma realidade/ normalidade com relevo e volume enquanto não houver a existência de uma pluralidade de vozes

"0 rótulo influencia enormemente nossa percepção do comportamento de um indivíduo, pois uma vez atribuído, nós temos a tendência a perceber seu comportamento de acordo com o rótulo imputado, mesmo diante de fatos que o contradigam" (NUNAN, 2003, p. 63). 
construindo e descontruindo aquilo que se acredita ser um homem gay em sua vida sexual.

Finalmente, podemos pensar que 0 texto da jornalista é completamente a-político ${ }^{11} \mathrm{em}$ seu sentido negativo, mas não no que tange à ausência de uma filiação partidária e/ou à propagação de uma ideologia (se bem que todo produto midiático é por excelência ideológico), mas porque exerce a distribuição das representações das imagens das sexualidades de forma arbitrária, alterando seus lugares e 0 cálculo da potencialidade dos corpos na real paisagem das sensações.

\section{Referências}

ANDRADE, G. Sexo como um gay. Happy Woman, Lisboa, n. 40, jun. 2009.

BADINTER, E. XY: sobre a identidade masculina. Rio de Janeiro: Nova Fronteira, 1993.

BARTHES, R. 0 óbvio e o obtuso. Rio de Janeiro: Nova Fronteira, 1990.

BERGER, P. L. Modernidade, pluralismo e crise de sentido: a orientação do homem moderno. Petrópolis, RJ: Vozes, 2004.

BORRILLO, D. Homofobia: história e crítica de um preconceito. Belo Horizonte: Autêntica, 2010.

BOURDIEU, P. Sobre a televisão seguido de a influência do jornalismo e os jogos olímpicos. Rio de
Janeiro: Editora Jorge Zahar, 1997.

COSTA, J. F. A inocência e o vício: estudos sobre 0 homoerotismo. Rio de Janeiro: Relume Dumará, 1992.

DEBORD, G. A sociedade do espetáculo. Rio de Janeiro: Contraponto, 1997.

DI FRANCO, C. A. Jornalismo, ética e qualidade. São Paulo: Vozes, 1995.

FERRAZ, S. B.; CAMPOS, Marília Romero. Com que corpo eu vou?: a moral da boa forma e a espetacularização da aparência na sociedade contemporânea. In: CONGRESSO BRASILEIRO DE CIÊNCIAS DA COMUNICAÇÃO (INTERCOM), 33., 2010. Caxias do Sul. Anais... Caxias do Sul: Sociedade Brasileira de Estudos Interdisciplinares da Comunicação, 2010.

FINK, B. 0 sujeito lacaniano: entre a linguagem e 0 gozo. Rio de Janeiro: Jorge Zahar,1998.

FOUCAULT, M. História da sexualidade I: a vontade de saber. Rio de Janeiro: Graal, 1985.

FOUCAULT, M. História da sexualidade 1: a vontade de saber. Rio de Janeiro: Graal, 1988.

FOUCAULT, M. Microfísica do poder. Rio de Janeiro: Graal, 1999.

GIDDENS, A. Modernidade e identidade. Rio de Janeiro: Jorge Zahar, 2002.

KELLNER, D. A cultura da mídia: estudos culturais: identidade e política entre o moderno e o pós-moderno. Bauru: EDUSC, 2001.

LE BRETON, D. Adeus ao corpo: antropologia e sociedade. Campinas, SP: Papirus, 2003.

10 Nas palavras de Di Franco (1995, p. 28), "[...] o respeito ao público, verdadeiro detentor da informação, e a fidelidade à verdade factual são as duas exigências do jornalismo competente". Essas duas características, como pude mostrar, não estão presentes na escrita de Andrade, visto que esta desrespeita o público homossexual ao promover uma série de "verdades" generalizantes sobre este grupo.

11 De acordo com o crítico francês Jacques Rancière (2010, p. 143), "[...] a política consiste, antes de mais nada em mudar os lugares e 0 cálculo dos corpos". 
LOUR0, G. L. Um corpo estranho: ensaios sobre sexualidade e teoria queer. Belo Horizonte: Autêntica, 2008.

NUNAN, A. Homossexualidade: do preconceito aos padrões de consumo. Rio de Janeiro: Caravansaraí, 2003.

RANCIÈRE, J. 0 espectador emancipado. Lisboa: Orfeu Negro, 2010.

SIBILIA, P. A vida como relato nos blogs: mutações no olhar introspectivo e retrospectivo na conformação do "eu". In: CONGRESSO LUSO-AFRO-BRASILEIRO DE CIÊNCIAS SOCIAIS, 8., 2004, Coimbra. Anais... Coimbra: Universidade de Coimbra, 2004. Disponível em: < http://www.ces.uc.pt/LAB2004>. Acesso em: 10 dez. 2013.

SIBILIA, P. 0s diários íntimos na Internet e a crise da interioridade psicológica. 2003. Disponível em: $<$ http://www.comunica.unisinos.br/tics/textos/2003/ GT12TB6.PDF > . Acesso em: 25 fev. 2014.

SIBILIA, P. 0 show do eu: a intimidade como espetáculo. Rio de Janeiro: Nova Fronteira, 2008. SIBILIA, P. 0 corpo editado e a carne impura. In: GARCIA, W. (Org.). Corpo e subjetividade: estudos contemporâneos. São Paulo: Factash, 2006.

SIMMEL, G. Fidelidade e gratidão e outros textos. Lisboa: Relógio D’Água, 2004.

THOMPSON, J. B. A mídia e a modernidade: uma teoria social da mídia. Petrópoles, RJ: Vozes, 1998.

VIRILIO, P. A arte do motor. São Paulo: Estação Liberdade, 1996.

ZAGO, G. S. 0 fenômeno da exposição de si na Internet.

Revista Eletrônica do Programa de Pós-graduação da Faculdade Cásper Líbero, São Paulo, v. 2, ano 2, dez. 2010. Disponível em: < http://www.revistas. univerciencia.org/index.php/comtempo > . Acesso em: 25 fev. 2014. 
Bodies in eternal ecstasy: a case study on cognitive homophobia in Portuguese Happy Woman magazine

\section{Órganos en éxtasis eterna: un estudio de caso sobre la homofobia cognitiva en la revista portuguesa Happy Woman}

\section{Abstract}

In 2009, the Portuguese varieties magazine aimed at female audiences Happy Woman published the article "Orgasm: make sex as a gay." Having as object of analysis that matter, this paper aims, through a critical analysis of journalistic discourse, identify homophobic aspects in a text that tries to prove theoretically, albeit conservatively, gay men as sexually active and happy subjects (or happy to be sexually active). To do so, the work will seek dialogue with communication theorists and sociologists who theorize about communication, as Bourdieu for example, as well as works of sociologists dealing with issues related to body and homophobia and / or homoeroticism in order, beyond the reach of the main objective of the research, see how the gay male body is constructed by the statements of the matter and how own ethical issues of journalism are violated in the discursive construction of these bodies.

\section{Keywords}

Cognitive homophobia. Sexual behavior. Male homosexuality.

\section{Resumen}

En 2009, la revista de variedades portuguesa dirigida a la audiencia femenina Happy Woman publicó el artículo "El orgasmo: hacer que el sexo como un gay." Teniendo como objeto de análisis de que la materia, el presente trabajo tiene como objetivo, a través de un análisis crítico del discurso periodístico, identificar aspectos homofóbicos en un texto que trata de demostrar teóricamente , aunque conservadora, los hombres gay como sujetos sexualmente activos y felices ( 0 feliz de ser sexualmente activos). Para ello, el trabajo será buscar el diálogo con los teóricos de la comunicación y los sociólogos que teorizan acerca de la comunicación a ejemplo de Bourdieu, así como obras de los sociólogos que se ocupan de cuestiones relacionadas con el cuerpo y la homofobia y /o homoerotismo en orden, más allá del alcance del objetivo principal de la investigación, ver cómo el cuerpo del hombre gay es construido por los estados de la materia y cómo las cuestiones éticas propias del periodismo se violan en la construcción discursiva de estos cuerpos.

\section{Palabras-Clave}

Homofobia cognitiva. El comportamiento sexual. La homosexualidad masculina. 


\section{Expediente}

A revista E-Compós é a publicação científica em formato eletrônico da Associação Nacional dos Programas de Pós-Graduação em Comunicação (Compós). Lançada em 2004, tem como principal finalidade difundir a produção acadêmica de pesquisadores da área de Comunicação, inseridos em instituições do Brasil e do exterior.

\section{E-COMPÓS I www.e-compos.org.br I E-ISSN 1808-2599}

Revista da Associação Nacional dos Programas

de Pós-Graduação em Comunicacão.

Brasília, v.17, n.1, jan./abri. 2014.

A identificação das edições, a partir de 2008

passa a ser volume anual com três números.

\section{CONSELHO EDITORIAL}

Afonso Albuquerque, Universidade Federal Fluminense, Brasil Alberto Carlos Augusto Klein, Universidade Estadual de Londrina, Brasil Alex Fernando Teixeira Primo, Universidade Federal do Rio Grande do Sul, Brasil Ana Carolina Damboriarena Escosteguy, Pontifícia Universidade Católica do Rio Grande do Sul, Brasi

Ana Gruszynski, Universidade Federal do Rio Grande do Sul, Brasil Ana Silvia Lopes Davi Médola, Universidade Estadual Paulista, Brasil André Luiz Martins Lemos, Universidade Federal da Bahia, Brasi Ângela Freire Prysthon, Universidade Federal de Pernambuco, Brasil Antônio Fausto Neto, Universidade do Vale do Rio dos Sinos, Brasil Antonio Carlos Hohlfeldt, Pontifícia Universidade Católica do Rio Grande do Sul, Brasil Antonio Roberto Chiachiri Filho, Faculdade Cásper Líbero, Brasi Arlindo Ribeiro Machado, Universidade de São Paulo, Brasil Arthur Autran Franco de Sá Neto, Universidade Federal de São Carlos, Brasil Benjamim Picado, Universidade Federal Fluminense, Brasil César Geraldo Guimarães, Universidade Federal de Minas Gerais, Brasil Cristiane Freitas Gutfreind, Pontifícia Universidade Católica do Rio Grande do Sul, Brasil Denilson Lopes, Universidade Federal do Rio de Janeiro, Brasil Denize Correa Araujo, Universidade Tuiuti do Paraná, Brasi Edilson Cazeloto, Universidade Paulista , Brasil

Eduardo Vicente, Universidade de São Paulo, Brasil Eneus Trindade, Universidade de São Paulo, Brasil Erick Felinto de Oliveira, Universidade do Estado do Rio de Janeiro, Brasi Florence Dravet, Universidade Católica de Brasília, Brasil Gelson Santana, Universidade Anhembi/Morumbi, Brasi Gilson Vieira Monteiro, Universidade Federal do Amazonas, Brasil Gislene da Silva, Universidade Federal de Santa Catarina, Brasil Guillermo Orozco Gómez, Universidad de Guadalajara Gustavo Daudt Fischer, Universidade do Vale do Rio dos Sinos, Brasil Hector Ospina, Universidad de Manizales, Colômbia Herom Vargas, Universidade Municipal de São Caetano do Sul, Brasil Ieda Tucherman, Universidade Federal do Rio de Janeiro, Brasil Inês Vitorino, Universidade Federal do Ceará, Brasil Janice Caiafa, Universidade Federal do Rio de Janeiro, Brasil Jay David Bolter, Georgia Institute of Technology Jeder Silveira Janotti Junior, Universidade Federal de Pernambuco, Brasi João Freire Filho, Universidade Federal do Rio de Janeiro, Brasil John DH Downing, University of Texas at Austin, Estados Unidos
José Afonso da Silva Junior, Universidade Federal de Pernambuco, Brasil José Carlos Rodrigues, Pontifícia Universidade Católica do Rio de Janeiro, Brasil José Luiz Aidar Prado, Pontifícia Universidade Católica de São Paulo, Brasil José Luiz Warren Jardim Gomes Braga, Universidade do Vale do Rio dos Sinos, Brasil Juremir Machado da Silva, Pontifícia Universidade Católica do Rio Grande do Sul, Brasil Laan Mendes Barros, Universidade Metodista de São Paulo, Brasil Lance Strate, Fordham University, USA, Estados Unidos Lorraine Leu, University of Bristol, Grã-Bretanha Lucia Leão, Pontifícia Universidade Católica de São Paulo, Brasil Luciana Panke, Universidade Federal do Paraná, Brasil Luiz Claudio Martino, Universidade de Brasília, Brasil Malena Segura Contrera, Universidade Paulista, Brasil Márcio de Vasconcellos Serelle, Pontifícia Universidade Católica de Minas Gerais, Brasil Maria Aparecida Baccega, Universidade de São Paulo e Escola Superior de Propaganda e Marketing, Brasil Maria das Graças Pinto Coelho, Universidade Federal do Rio Grande do Norte, Brasil Maria Immacolata Vassallo de Lopes, Universidade de São Paulo, Brasil Maria Luiza Martins de Mendonça, Universidade Federal de Goiás, Brasil Mauro de Souza Ventura, Universidade Estadual Paulista, Brasil Mauro Pereira Porto, Tulane University, Estados Unidos Nilda Aparecida Jacks, Universidade Federal do Rio Grande do Sul, Brasil Paulo Roberto Gibaldi Vaz, Universidade Federal do Rio de Janeiro, Brasil Potiguara Mendes Silveira Jr, Universidade Federal de Juiz de Fora, Brasil Renato Cordeiro Gomes, Pontifícia Universidade Católica do Rio de Janeiro, Brasil Robert K Logan, University of Toronto, Canadá

Ronaldo George Helal, Universidade do Estado do Rio de Janeiro, Brasil Rosana de Lima Soares, Universidade de São Paulo, Brasil Rose Melo Rocha, Escola Superior de Propaganda e Marketing, Brasil Rossana Reguillo, Instituto de Estudos Superiores do Ocidente, Mexico Rousiley Celi Moreira Maia, Universidade Federal de Minas Gerais, Brasi Sebastião Carlos de Morais Squirra, Universidade Metodista de São Paulo, Brasil Sebastião Guilherme Albano da Costa, Universidade Federal do Rio Grande do Norte, Brasil

Simone Maria Andrade Pereira de Sá, Universidade Federal Fluminense, Brasil Tiago Quiroga Fausto Neto, Universidade de Brasilia, Brasil Suzete Venturelli, Universidade de Brasília, Brasil Valerio Fuenzalida Fernández, Puc-Chile, Chile Veneza Mayora Ronsini, Universidade Federal de Santa Maria, Brasil Vera Regina Veiga França, Universidade Federal de Minas Gerais, Brasil

\section{COMISSÃO EDITORIAL}

Cristiane Freitas Gutfreind I Pontifícia Universidade Católica do Rio Grande do Sul, Brasil Irene Machado I Universidade de São Paulo, Brasil

Jorge Cardoso Filho I Universidade Federal do Reconcavo da Bahia, Brasil / Universidade Federal da Bahia, Brasil

CONSULTORES AD HOC

Adriana Amaral, Universidade do Vale do Rio dos Sinos, Brasil

Alexandre Rocha da Silva, Universidade Federal do Rio Grande do Sul, Brasi Arthur Ituassu, Pontifícia Universidade Católica do Rio de Janeiro, Brasil Bruno Souza Leal, Universidade Federal de Minas Gerais, Brasil Elizabeth Bastos Duarte, Universidade Federal de Santa Maria, Brasil Francisco Paulo Jamil Marques, Universidade Federal do Ceará, Brasi Maurício Lissovsky, Universidade Federal do Rio de Janeiro, Brasil Suzana Kilpp, Universidade do Vale do Rio dos Sinos, Brasil Vander Casaqui, Escola Superior de Propaganda e Marketing, Brasil

EDIÇÃO DE TEXTO E RESUMOS I Susane Barros SECRETÁRIA EXECUTIVA I Helena Stigger EDITORAÇÃo ELETRÔNICA I Roka Estúdio
COMPÓS I www.compos.org.br

Associação Nacional dos Programas de Pós-Graduação em Comunicação

Presidente

Eduardo Morettin

Universidade de São Paulo, Brasil

eduardomorettin@usp.br

Vice-presidente

Inês Vitorino

Universidade Federal do Ceará, Brasil

ines@ufc.br

Secretária-Geral

Gislene da Silva

Universidade Federal de Santa Catarina, Brasil

gislenedasilva@gmail.com 